\title{
O apagamento do /s / pós-vocálico numa favela do Rio de Janeiro
}

\author{
Postvocalic /s/ deletion in a Rio de Janeiro favela
}

\author{
Edvan P. Brito*
}

University of Arkansas

Fayetteville, Arkansas, Estados Unidos.

\begin{abstract}
Resumo: Este artigo faz uma análise sociolinguística do apagamento do / s / pós-vocálico em final de palavra na fala de moradores da Cidade de Deus, bairro majoritariamente negro localizado na zona oeste da cidade do Rio de Janeiro. O corpus é composto por dezessete entrevistas realizadas no ano de 2015 com vinte e duas pessoas. $\mathrm{Na}$ análise quantitativa foram incluídas seis variáveis linguísticas (vogal precedente, contexto seguinte, tonicidade, número de sílabas, classe gramatical, e palavra, como efeito aleatório) e seis variáveis sociais (faixa etária, sexo, raça ou cor, origem regional, nível de escolaridade e falante, como efeito aleatório). Os dados foram analisados por regressão logística usando o programa RBrul, cujo resultado revelou que todas as variáveis linguísticas, exceto palavra, foram selecionadas como significantes para o apagamento do /s/. Entre as variáveis sociais, apenas faixa etária e nível de escolaridade ficaram nesta categoria. Este artigo contribui para a área de estudos de variação sociolinguística do português brasileiro com uma análise de dados linguísticos oriundos de um tipo de comunidade que não tem recebido muita ênfase nesta área e com uma abordagem metodológica inovadora que inclui a identidade racial e a origem regional dos participantes como fatores importantes para se compreender a realidade linguística destas comunidades urbanas.
\end{abstract}

Palavras-chave: /s/ pós-vocálico. Variação sociolinguística. Favela. Raça ou cor. Migração

\begin{abstract}
This article carries out a sociolinguistic analysis of postvocalic /s/ deletion in word-final position in the speech of residents of City of God, a predominantly black neighborhood located in the West Zone of Rio de Janeiro city. The corpus consists of seventeen interviews done in 2015 with twenty-two people. The quantitative analysis of the data included six linguistic variables (preceding vowel, following segment, stress, number of syllables, grammatical category, and word as a random effect) and six social variables (age, sex, race or color, regional origin, level of education, and speaker, as a random effect). The data were analyzed with logistic regression using RBrul. The results showed that all the linguistic variables but word were selected as significant for /s/ deletion. Among the social variables, only age and level of education were in this category. This paper contributes to the area of study of Brazilian Portuguese sociolinguistic variation by providing an analysis of linguistic data from a type of community that has not received much attention in this area and by using an innovative approach that includes racial identity and regional origin as important factors to understand the linguistic reality of these urban communities.
\end{abstract}

Keywords: Postvocalic /s/. Sociolinguistic variation. Favela. Race or color. Migration

\section{INTRODUÇÃO}

Inspirados no grande legado da área da Dialetologia, os primeiros estudos teóricos e empíricos na área de Sociolinguística Variacionista surgiram nos Estados Unidos na segunda metade da década de 1960. Entre estas pesquisas pioneiras estão os estudos de Weinreich, Labov e Herzog (1968) e os estudos de Labov (1963, 1966) em Martha's

\footnotetext{
*University of Arkansas, Fayetteville, Arkansas, Estados Unidos. E-mail: brito@uark.edu
} 
Vineyard e na cidade de Nova Iorque, os quais delinearam alguns dos fundamentos para o estudo sistemático de diversos processos de variação e mudança linguística. No Brasil, os primeiros estudos dentro da área de Sociolinguística começaram a aparecer já no início da década de 1970, impulsionando o desenvolvimento da área nas décadas seguintes. Para além do fazer científico, o aumento do número de estudos nesta área ao longo das últimas décadas tem ampliado a discussão sobre a legitimidade de variedades e variantes linguísticas estigmatizadas e com pouco ou nenhum prestígio social.

Dentro dessa perspectiva, o presente artigo faz uma análise sociolinguística do /s / pós-vocálico em final de palavra na fala de moradores da Cidade de Deus, bairro majoritariamente negro localizado na zona oeste da cidade do Rio de Janeiro. O foco desta análise é a variante zero, que se configura como a variante mais estigmatizada dessa variável por ser geralmente associada à fala de pessoas com baixo status socioeconômico e baixo nível de escolaridade. Portanto, busca-se compreender como fatores linguísticos e sociais afetam a ocorrência dessa variante na fala de indivíduos e grupos da referida comunidade, levando em consideração alguns dos aspectos sociais e históricos que caracterizam a sua existência. Desse modo, o presente estudo contribui para a área de estudos de variação linguística do português brasileiro, sobretudo a área de estudos sobre o /s/ pós-vocálico, de pelo menos duas formas. Uma delas é a apresentação e análise de dados linguísticos coletados em uma comunidade urbana popularmente conhecida como uma favela, que é um tipo de comunidade que não tem recebido muita ênfase em estudos de variação linguística no Brasil. A outra contribuição diz respeito à problematização do conceito de favela, o que nos leva a oferecer uma abordagem inovadora nesta área de estudos ao incluir a identidade de raça ou cor e a origem regional dos participantes como fatores relevantes para o entendimento do seu repertório linguístico.

\subsection{O APAGAMENTO DO /S/ PÓS-VOCÁLICO}

Por conta do seu alto grau de variabilidade e de suas motivações tanto fonológicas quanto morfossintáticas, o /s/ pós-vocálico é uma das variáveis mais estudadas na área de estudos sociolinguísticos brasileiros. O /s / pós-vocálico tem quatro variantes que representam suas seis realizações fonéticas: 1) a variante alveolar, que corresponde às fricativas alveolares surda [s] e sonora [z]; 2) a variante palatal, que representa as fricativas pós-alveolares surda [J] e sonora [3]; a variante aspirada [h]; e por fim, a variante zero [ø]. Os estudos sobre palatalização do /s/ são certamente os mais numerosos, mas tem havido um crescente interesse pelas variantes aspirada (e.g., AULER, 1992; BRESCANCINI, 2004; BRITO, 2019; MELO, 2017) e zero (e.g., FERREIRA, 2001; GUY, 1981; GRYNER; MACEDO, 2000).

$\mathrm{Na}$ interface entre a Fonologia e a Morfossintaxe, o apagamento tanto do fonema /s/ quanto do morfema de plural -s é provavelmente a variante mais estudada devido à sua conexão com as regras variáveis do sintagma nominal no português brasileiro (GUY 1981, 2014). No campo da Fonologia, boa parte dos estudos se concentra em compreender os processos de variação e mudança na evolução da variante alveolar para as demais variantes do /s/ pós-vocálico. Segundo alguns autores (CALLOU; LEITE; MORAES, 2002; SCHERRE; MACEDO, 2000), este seria um processo de 
enfraquecimento gradativo da variante alveolar, que passaria para palatal, depois para aspirada e, ao final, apagada. Apesar de considerar alguns dos aspectos morfossintáticos que restringem a variação do /s/ pós-vocálico no português brasileiro, o presente estudo discute principalmente os aspectos fonológicos deste processo.

A análise da variante zero foi incorporada numa série de estudos sociolinguísticos sobre o /s / pós-vocálico em várias regiões do Brasil. Alguns exemplos incluem os estudos de Brescancini (2002, 2006), Callou (2009), Callou e Brandão (2009), Callou, Leite e Moraes (2002), Ferreira (2001), Lucchesi (2009), Hora (2003), Hora e Pedrosa (2009), Hora, Pedrosa e Cardoso (2010) e Mota (2002). No restante desta seção, serão revisados alguns dos principais estudos que discutiram o uso do apagamento do /s/ pós-vocálico no português falado na cidade do Rio de Janeiro.

Um dos primeiros estudos sociolinguísticos sobre a variável /s/ pós-vocálico no português carioca foi realizado por Callou e Marques (1975). Neste estudo, as autoras analisaram dados que foram coletados entre 1970 e $1972 \mathrm{em}$ cinco regiões da cidade do Rio de Janeiro. Trinta e seis pessoas com idades entre 20 e 45 anos participaram do estudo. Das 2.669 ocorrências da variável em posição medial e final coletadas, apenas 83 casos $(3.2 \%)$ eram de apagamento do / s . Nota-se também o efeito do nível de escolaridade na ocorrência desta variante, de modo que o seu aparecimento tende a diminuir na medida em que o nível de escolaridade dos falantes aumenta. O uso desta variável por homens $(3,3 \%)$ e mulheres $(2,9 \%)$ não apresentou uma grande diferença.

O apagamento do /s/ pós-vocálico em final de vocábulo foi um dos elementos analisados por Guy (1981) em seu estudo sobre a fala de um grupo de vinte informantes cariocas analfabetos e integrantes da classe trabalhadora. O grupo era formado por nove mulheres e onze homens que estudavam no antigo MOBRAL (Movimento Brasileiro de Alfabetização). Nesse estudo, Guy analisou um corpus composto por 10.271 ocorrências de /s / pós-vocálico, das quais 1.298 (13\%) eram de apagamento. É importante lembrar que esses dados foram extraídos de palavras monomorfêmicas, isto é, palavras cujo -s final é parte integrante do seu radical. Dos grupos de fatores linguísticos analisados, Guy observou que a tonicidade da sílaba em que o / s / ocorre teve um efeito significativo para o apagamento. Nesse grupo, a variante foi favorecida por palavras oxítonas (.86) e desfavorecida por monossílabos tônicos (.24) e polissílabos não oxítonas (.34). A tonicidade da sílaba seguinte ao / $/$ t também afetou significativamente o seu apagamento, sendo que sílabas átonas tiveram um efeito levemente positivo (.57) e sílabas tônicas (.43), um efeito levemente negativo. Quanto ao contexto seguinte, a probabilidade de o apagamento acontecer diante de consoantes, principalmente as vozeadas, foi maior do que diante das vogais. Pausa teve um efeito neutro para a ocorrência desta variante. Analisando o efeito do estilo de fala, os resultados mostraram que o apagamento foi mais favorecido no estilo casual (.55) do que no cuidadoso (.45). Os homens (.55) apagaram mais o /s/ do que as mulheres (.45). Entre as três faixas etárias incluídas na análise, o pagamento foi levemente favorecido pelas pessoas com idades entre 18 e 30 anos (.54) e levemente desfavorecido pelas pessoas com idades entre 15 e $18(.47)$ e com mais de 30 anos (.48).

Um outro estudo importante sobre o condicionamento linguístico e social do /s/ pós-vocálico foi feito por Scherre e Macedo (2000). Participaram da pesquisa 64 
indivíduos que foram entrevistados para o Corpus Censo entre 1980 e 1983. As autoras analisaram 7.500 ocorrências dessa variável em posição medial e final, das quais $732(10 \%)$ eram de apagamento. A análise estatística dos dados apontou que esta variante foi desfavorecida depois de vogais altas e anteriores (.38) e favorecida nos demais casos (.74). Dos contextos seguintes analisados, o apagamento do / s / foi significativamente positivo antes da fricativa sonora [v] (.77), das nasais sonoras [m] e [n] (.71) e das oclusivas sonoras [b], [d] e [g] (.66) e negativo antes de pausa (.44) e das oclusivas surdas [p], [t] e [k] (.41). A lateral sonora [1] teve um efeito neutro para a ocorrência do zero fonético. Esta variante também foi desfavorecida em contexto interno e favorecida em contexto final de palavra em monossílabos (.77), palavras oxítonas com mais de uma sílaba (.83) e palavras nãooxítonas com mais de uma sílaba (.90). Por fim, no grupo de fatores que incluía algumas classes gramaticais e alguns itens lexicais, o apagamento do /s/ foi favorecido pelo morfema verbal -mos (.85) e a conjunção mas (.75) e desfavorecido por numerais (.18), substantivos comuns (.38) e verbos (.38). Na comparação com os demais fatores, tiveram um efeito neutro nesta variável as conjunções e advérbios (.58), o advérbio mais (.55), os adjetivos (.47) e os substantivos próprios (.41).

Analisando esses estudos sobre a variação sociolinguística do /s/ pós-vocálico no português falado na cidade do Rio de Janeiro, é possível fazer uma compilação com algumas das principais restrições linguísticas e sociais do apagamento do /s/. Um dos aspectos mais importantes do condicionamento linguístico envolvendo esta variante são os processos assimilatórios envolvendo tanto a vogal precedente ao /s/ quanto o contexto sonoro seguinte. No caso da vogal precedente, estudos anteriores mostram que há uma probabilidade maior de o / s / ser apagado quando precedido por vogais não altas e não anteriores. Há também uma ocorrência maior dessa variante quando ela é seguida por consoantes vozeadas. Os estudos de Guy (1981) e Scherre e Macedo (2000) divergem um pouco quanto ao efeito da tonicidade da sílaba em que o / s/ aparece. No primeiro caso, o apagamento foi fortemente favorecido em sílabas finais átonas e, no segundo, essa variante foi fortemente favorecida em final de palavra tanto em sílabas átonas quanto tônicas. Quanto à variável sexo, destaca-se que os homens tendem a apagar mais o /s/ do que as mulheres. Considerando o estudo de Guy (1981), pode-se dizer que a variável faixa etária teve um efeito quase neutro no apagamento do/s/, exceto pelo fato de que houve maior incidência dessa variante entre adultos jovens (18 a 30 anos). Por fim, essa variante é mais frequente na fala de pessoas com nível de escolaridade mais baixo, o que foi observado por Callou e Marques (1975) e corroborado por outros estudos (GRYNER; MACEDO, 2000). Considerando os resultados das pesquisas discutidas nesta seção, o presente estudo se baseia nos princípios da Sociolinguística Variacionista para fazer uma análise quantitativa da ocorrência do apagamento do /s/ pós-vocálico em contexto de final de palavra na fala de indivíduos e grupos de moradores da Cidade de Deus.

\subsection{CIDADE DE DEUS: FAVELA, RAÇA E MIGRAÇÃO}

Ao tomar a Cidade de Deus como exemplo, este trabalho questiona o conceito de favela discutindo as divergências conceituais entre a definição oficial adotada pelo 
Instituto Brasileiro de Geografia e Estatística - IBGE (2011) e a percepção que as pessoas têm sobre esse termo. Outro ponto importante nessa discussão é a ideia de que qualquer estudo sobre favelas, independentemente da definição que se adote, deve incorporar um aprofundamento da questão étnico-racial e dos processos de migração interna, que são elementos fundamentais para se entender o surgimento e o desenvolvimento dessas áreas no contexto dos grandes centros urbanos.

O IBGE (2011) utiliza o termo genérico 'aglomerado subnormal' para caracterizar os diversos modos de ocupação informal da terra e sua precária infraestrutura. Pode-se dizer que favela é um tipo de aglomerado subnormal e é também o termo que está mais presente no imaginário coletivo, especialmente no Sudeste e Sul do Brasil. Entretanto, se na teoria favela é um tipo de aglomerado subnormal, na prática essa relação não se sustenta. Por exemplo, do ponto de vista técnico, a Cidade de Deus não é um aglomerado subnormal e, portanto, também não é uma favela, já que, segundo dados do Instituto Pereira Passos (CAVALLIERI; VIAL, 2010), apenas 13\% do seu território se enquadra nos critérios que o IBGE usa para determinar se uma área é ou não é um aglomerado subnormal. Na verdade, a Cidade de Deus é uma das trinta e três regiões administrativas e um dos 160 bairros do município do Rio de Janeiro. Mas, se esse é o caso, por que a relação entre esse lugar e o termo favela persiste?

Além do papel desempenhado pela mídia em ajudar a consolidar essa ideia por meio de sua cobertura (e.g., noticiários, livros, filmes etc.), isso acontece também pelo fato de que o conceito de aglomerado subnormal levar em conta critérios materiais e legais, como número de habitações, infraestrutura e posse do imóvel, enquanto o termo favela vai além desses critérios e engloba uma série de características reais ou imaginárias dos seus residentes. Tais características têm a ver com o modo como os indivíduos se identificam ou são identificados por outros em termos de raça ou cor, classe social, origem regional, vestimenta, linguagem corporal, e também seu modo de falar (BRITO, 2019; PERLMAN, 2000; ROTH-GORDON, 2017).

No caso da identidade étnico-racial, isso é relevante porque essas áreas são desproporcionalmente habitadas por pessoas negras, isto é, pessoas que se autodeclaram pretas e pardas no censo do IBGE. Estima-se que pelo menos $66 \%$ das pessoas que moram em áreas consideradas aglomerados subnormais sejam negras (IPEA, 2011). Os resultados do Instituto Data Favela revelam que essa porcentagem nacional é de $72 \%$ (MEIRELLES; ATHAIDE, 2014). De acordo com o censo 2010, a Cidade de Deus tem uma população de 36.515 habitantes, dos quais $52 \%$ se autodeclaram pardos, 20,6\% pretos, 26,1\% brancos e 1,2\% asiáticos (IBGE, 2011). Além de as análises estatísticas apontarem para a predominância de pessoas negras habitando favelas, no imaginário coletivo essa relação entre favela e negritude é bem mais próxima do se imagina (BEATON; WASHINGTON, 2014; VARGAS 2004, p. 455, apud ROTH-GORDON, 2017, p. 24).

No contexto das grandes metrópoles do Sudeste e Sul do Brasil, tais como Rio de Janeiro e São Paulo, favelas também são identificadas como áreas habitadas por migrantes pobres de todas as partes do país, especialmente das regiões Norte e Nordeste. Essa migração tem uma longa história, mas se intensificou em meados do século XX com o crescente processo de industrialização dos grandes centros urbanos do Sudeste e Sul. Para 
se ter uma ideia, de acordo com o censo 2010, os nordestinos representam 37,9\% das pessoas que imigraram para o Rio de Janeiro (IPP, 2013). Com o fluxo intenso de pessoas chegando e saindo dessas grandes cidades, é de se esperar que haja um constante processo de convergência e divergência entre os traços linguísticos existentes nas comunidades de origem dessas pessoas e os traços que elas encontram nas comunidades que as recebem. Diante dessa constatação, é importante que o debate sobre a composição demográfica dos aglomerados subnormais ou favelas esteja no centro da discussão sobre essas comunidades, quer se opte pela definição oficial ou pela definição popular. Com isso, espera-se que as desigualdades tanto sociais quanto raciais sejam evidenciadas para que se tenha uma descrição mais realista sobre a vida das pessoas que ocupam esses espaços.

\section{METODOLOGIA}

Os dados analisados neste trabalho foram coletados em 2015 na Cidade de Deus, bairro predominantemente negro localizado na zona oeste da cidade do Rio de Janeiro. As entrevistas foram coletadas com um gravador digital e duraram em média 40 minutos. A maioria delas foi realizada na casa dos próprios informantes e na presença de alguns de seus familiares ou amigos, os quais participaram como ouvintes. Sendo assim, o clima das entrevistas foi bastante agradável. O questionário para as entrevistas (ver Anexo 1) foi traduzido e adaptado de um modelo usado no Projeto Lingua e Comunicação, sediado em Washington, D.C. (Language and Communication in Washington, D.C. Project) (NYLUND, 2013, p. 291-292) (Ver também BRITO, 2019). Os principais tópicos abordados nas entrevistas foram a trajetória de vida dos moradores, o seu dia a dia dentro e fora da comunidade, as diferenças entre a Cidade de Deus e outros bairros, discriminação residencial, entre outros.

Foram realizadas dezessete entrevistas com vinte e dois moradores adultos da Cidade de Deus. A discrepância entre o número de entrevistas e o número de entrevistados se deve ao fato de que alguns participantes foram entrevistados em grupo, o que ajudou a minimizar o que Labov (1972b, p. 113) chama de o paradoxo do observador, a ideia de que "para obter os dados mais importantes para a teoria linguística, nós temos que observar como as pessoas falam quando elas não estão sendo observadas." O recrutamento dos falantes para a pesquisa foi feito usando a técnica de amostragem conhecida como bola de neve (MILROY; GORDON, 2003; SCHILLING, 2013), na qual o grupo inicial de informantes é geralmente formado por amigos ou conhecidos do pesquisador ou da pesquisadora e estes posteriormente indicam outros potenciais participantes, e assim sucessivamente.

O principal instrumento de coleta de dados foi a entrevista sociolinguística (LABOV, 1972a, 1972b). Tradicionalmente usada para a coleta de dados linguísticos na área de Sociolinguística Variacionista, a entrevista sociolinguística é geralmente composta por diferentes etapas, a saber leitura, lista de palavras, pares mínimos e a entrevista propriamente dita. Segundo Labov (1972a), tais técnicas serviriam para levar os falantes a produzir amostras de uso da língua dentro de diferentes níveis de formalidade. Mesmo reconhecendo que a entrevista em si é um tipo de interação relativamente formal, o 
objetivo do pesquisador é conseguir amostras de fala espontânea ou casual, que estariam mais próximas do vernáculo da língua, isto é o estilo linguístico em que o falante presta menos atenção à fala (LABOV, 1972a). A justificativa metodológica para o uso da entrevista como único instrumento de coleta de dados foi o fato de que a pesquisa incluiria falantes de diversos níveis de escolaridade, independente do seu grau de letramento.

Os vinte e dois participantes foram distribuídos por sexo (16 do sexo feminino e 6 do sexo masculino), faixa etária (18 a 35 anos, 36 a 55 anos e mais 56 anos), nível de escolaridade ( 8 entre 0 e 8 anos de educação formal, 11 entre 9 e 12 e 3 com mais de 12 anos), origem (11 nascidos na cidade do Rio de Janeiro, 3 nascidos no estado do Rio de Janeiro, 5 nascidos em outros estados da região Sudeste e 3 oriundos da região Nordeste) e raça ou cor (10 negros, 10 pardos e 2 brancos). Esta pesquisa foi aprovada pelo Comitê de Ética da Georgetown University, sob o protocolo número 2015-0355.

Nas dezessete entrevistas, foram coletadas 4.804 ocorrências do / s/ pós-vocálico em final de palavra. Dentre essas, $3.212(66.8 \%)$ foram da variante palatal, $730(15.2 \%)$ de apagamento, $440(9.2 \%)$ de alveolar e $422(8.8 \%)$ da variante aspirada. Cada ocorrência da variável foi codificada de acordo com seis variáveis independentes, a saber: vogal precedente (anterior, central e posterior), contexto seguinte (coronal, dorsal, labial e pausa), tonicidade (sílaba átona e tônica), número de sílabas (monossílabo, dissílabo, trissílabo e polissílabo), classe gramatical (adjetivo, advérbio, artigo, conjunção, substantivo, numeral, pronome e verbo) e palavra, como efeito aleatório. Não foram incluídas na análise as ocorrências do /s/ pós-vocálico entre vogais ou antecedendo os fonemas [s], [f], [z], [3] e [h], assim como em contextos de realização duvidosa. Os resultados da análise sociolinguística dos dados serão analisados e discutidos na próxima seção.

\section{ANÁLISE E DISCUSSÃO DOS RESULTADOS}

A análise quantitativa dos dados foi feita com base no procedimento estatístico de regressão logística, utilizando-se a função one-level analysis do Rbrul (JOHNSON, 2009). Este procedimento estatístico analisou o efeito de seis grupos de fatores linguísticos (vogal precedente, contexto seguinte, tonicidade da sílaba em que o /s/ aparece, número de sílabas, classe gramatical e palavra, como efeito aleatório) e seis grupos de fatores extralinguísticos (sexo, faixa etária, nível de escolaridade, origem, raça ou cor e falante, como efeito aleatório) na ocorrência da variável /s/ pós-vocálico. Para este processo, a variante zero foi considerada como o valor de aplicação contra as outras três variantes (a palatal, a alveolar e a aspirada), que foram incluídas na análise como valores de nãoaplicação. Os resultados da análise de regressão logística dos dados são apresentados na Tabela 1, na qual as variáveis independentes aparecem por ordem de significância.

Tabela 1. Efeito das variáveis linguísticas e sociais no apagamento do /s / pós-vocálico

\begin{tabular}{l|l|l|r}
\hline \multicolumn{3}{c}{ Apagamento do /s/ Pós-vocálico (Valor de Aplicação) } \\
\hline Probabilidade & & & 0,01 \\
\hline Log likelihood & & & $-1186,418$ \\
\hline
\end{tabular}




\begin{tabular}{|c|c|c|c|}
\hline Total N & & & 4804 \\
\hline & Peso Relativo & Porcentagem & Total \\
\hline \multicolumn{4}{|c|}{ Classe Gramatical $(<.001)$} \\
\hline Substantivo & .86 & 29 & 1757 \\
\hline Adjetivo & .75 & 22 & 345 \\
\hline Advérbio & .70 & 03 & 487 \\
\hline Verbo & .64 & 24 & 335 \\
\hline Pronome & .54 & 03 & 672 \\
\hline Conjunção & .22 & 01 & 308 \\
\hline Numeral & .17 & 01 & 225 \\
\hline Artigo & .13 & 01 & 675 \\
\hline \multicolumn{4}{|c|}{ Vogal precedente $(\mathrm{p}<.001)$} \\
\hline Posterior & .65 & 25 & 1505 \\
\hline Central & .55 & 18 & 1528 \\
\hline Anterior & .29 & 04 & 1771 \\
\hline \multicolumn{4}{|c|}{ Tonicidade da sílaba $(\mathrm{p}<.001)$} \\
\hline Átona & .71 & 23 & 2960 \\
\hline Tônica & .29 & 02 & 1844 \\
\hline \multicolumn{4}{|c|}{ Contexto seguinte $(\mathrm{p}>.001)$} \\
\hline Pausa & .58 & 25 & 1397 \\
\hline Coronal & .56 & 16 & 1352 \\
\hline Labial & .51 & 08 & 1321 \\
\hline Dorsal & .34 & 08 & 734 \\
\hline \multicolumn{4}{|c|}{ Número de sílabas $(\mathrm{p}>.001)$} \\
\hline Polissílabo & .65 & 39 & 201 \\
\hline Trissílabo & .62 & 31 & 802 \\
\hline Dissílabo & .41 & 22 & 1674 \\
\hline Monossílabo & .30 & 01 & 2127 \\
\hline \multicolumn{4}{|c|}{ Faixa Etária $(=.01)$} \\
\hline Mais de 56 & .84 & 20 & 2998 \\
\hline $36-55$ & .41 & 08 & 1532 \\
\hline $18-35$ & .21 & 04 & 274 \\
\hline \multicolumn{4}{|c|}{ Nível de escolaridade $(=.04)$} \\
\hline $0-8$ & .63 & 22 & 1696 \\
\hline $9-12$ & .45 & 12 & 2121 \\
\hline Mais de 12 & .40 & 11 & 987 \\
\hline \multicolumn{4}{|c|}{ Raça ou cor (Não significante) } \\
\hline Preta & .60 & 14 & 1651 \\
\hline Parda & .48 & 16 & 2893 \\
\hline Branca & .41 & 14 & 260 \\
\hline \multicolumn{4}{|c|}{ Origem/Local de Nascimento (Não significante) } \\
\hline Sudeste & .67 & 26 & 493 \\
\hline
\end{tabular}




\begin{tabular}{l|c|c|c}
\hline Nordeste & .55 & 22 & 906 \\
\hline RJ Cidade & .46 & 11 & 2891 \\
\hline RJ Estado & .31 & 16 & 514 \\
\hline Sexo (Não significante) & .56 & 15 & 1066 \\
\hline Masculino & .43 & 15 & 3738 \\
\hline Feminino & \multicolumn{1}{l}{} \\
\hline \multicolumn{4}{l|}{ Falante (efeito aleatório) } \\
\hline \multicolumn{4}{l}{ Palavra (efeito aleatório) }
\end{tabular}

A seguir, serão discutidos e analisados os resultados apresentados na Tabela $1 \mathrm{em}$ duas subseções, uma tratando das variáveis linguísticas e outra das variáveis sociais.

\subsection{RESTRIÇÕES LINGUÍSTICAS DO APAGAMENTO DO /S/ PÓS- VOCÁLICO}

No presente estudo, a análise quantitativa dos dados verificou o efeito de seis variáveis linguísticas na ocorrência da variante zero. Estas variáveis foram vogal precedente, contexto seguinte, tonicidade, número de sílabas e classe gramatical. De acordo com os resultados obtidos a partir da análise de regressão logística dos dados, apresentados na Tabela 1, todas as variáveis linguísticas, exceto palavra, foram selecionadas como significantes para o apagamento do /s/ pós-vocálico.

Dentre os grupos de fatores incluídos na análise, classe gramatical foi o que teve maior influência no apagamento do /s/ pós-vocálico. Esta variante foi favorecida por substantivos (.86), adjetivos (.75), advérbios (.70) e verbos (.64). Enquanto os pronomes (.54) tiveram um efeito neutro na não realização do / s/ pós-vocálico, as conjunções (.22), os numerais (.17) e os artigos (.13) tiveram um efeito fortemente negativo. No caso destes últimos três fatores, é importante destacar que o / s/ foi apagado em apenas 1\% dos casos em cada um desses fatores, indicando que esse fenômeno não ocorre com frequência nessas classes gramaticais.

Esses resultados não são tão surpreendentes, especialmente se consideramos que neste estudo a variável estudada representa tanto o fonema /s/ quanto o morfema -s de plural. Sendo assim, o fato de o / $/$ ser apagado em substantivos e adjetivos e retido em artigos e numerais aponta para a regra de variação do sintagma nominal do português brasileiro, principalmente a sua variedade popular. Segundo essa regra, o apagamento do morfema de plural tende a ocorrer nos constituintes que aparecem mais à direita dentro do sintagma nominal, posição que é geralmente ocupada por substantivos e adjetivos. Como artigos e numerais tendem a ocupar posições mais à esquerda, há mais chances de o /s/ ser retido nestas classes gramaticais (GUY, 1981, 2014; RODRIGUES; HORA, 2016). O que os resultados aqui discutidos mostram é que a probabilidade de isso acontecer não é fortuita. 
No caso dos verbos, todos os 81 casos de apagamento do /s/ acontecem no morfema verbal -mos. Esse dado corrobora o resultado encontrado por Scherre e Macedo (2000) e Gryner e Macedo (2000) quanto ao efeito positivo deste morfema no apagamento da variável. Os resultados também indicam que há uma probabilidade maior de o apagamento ocorrer em advérbios e pronomes do que em conjunções, mas é preciso cautela para interpretar esses dados, principalmente com relação aos advérbios. Isso porque, das 487 ocorrências de /s/ pós-vocálico coletadas em advérbios, apenas 16 foram de apagamento. Desses 16 casos, 6 ocorreram no advérbio mais e 5 no advérbio menos. No caso dos pronomes, a interpretação de neutralidade é mais plausível do que a de leve efeito positivo, já que o apagamento ocorreu em apenas 23 casos num total de 672 ocorrências. Por fim, os resultados parecem ser mais confiáveis no caso das conjunções, visto que seu efeito negativo é corroborado pelo fato de que, das 308 conjunções que aparecem nos dados, apenas uma foi teve o / s / final apagado.

O segundo grupo de fatores selecionado como significante para a não realização do /s/ pós-vocálico foi vogal precedente. Neste grupo, a variante zero foi favorecida quando $\mathrm{o} / \mathrm{s} / \mathrm{em}$ final de palavra foi precedido por vogais posteriores (.65) e desfavorecida quando precedida por vogais anteriores (.29). Vogais centrais (.55) tiveram um efeito neutro para a ocorrência desta variante. Esse resultado já era esperado devido à influência assimilatória que a vogal precedente exerce na variação do /s/, como já foi atestado em outros estudos (SCHERRE; MACEDO, 2000).

A tonicidade da sílaba em que o / s/ aparece foi o próximo grupo de fatores significativamente relevante para a ocorrência da variante zero em final de palavra. Esta variante foi favorecida quando a última sílaba da palavra era átona (.71) e desfavorecida quando a última sílaba era tônica (.29). Este resultado confirma o que Gryner e Macedo (2000) verificaram no português falado na região de Cordeiro no centro-norte do estado do Rio de Janeiro mas diverge dos resultados de Guy (1981) e Scherre e Macedo (2000). No estudo de Guy, foram as sílabas tônicas, excetuando as palavras monossilábicas, que tiveram um efeito favorecedor nesta variante. Talvez isso tenha a ver com o fato de que a análise de Guy se restringe a palavras monomorfêmicas, o que não é o caso deste estudo. No estudo de Scherre e Macedo, o apagamento foi favorecido em monossílabos e polissílabos átonos e tônicos, com maior efeito positivo nas sílabas finais átonas (.90).

O contexto seguinte também teve um efeito significativo para o apagamento do $/ \mathrm{s} /$ pós-vocálico. Neste grupo, a ocorrência de pausa (.58) e de consoantes coronais (.56) teve um leve efeito favorecedor para a regra de aplicação em questão. As consoantes dorsais (.34), por outro lado, desfavoreceram a ocorrência da variante zero. Já as consoantes labiais (.51) tiveram um efeito neutro. O efeito positivo de pausa no apagamento do /s/ confirma o resultado encontrado por Gryner e Macedo (2000) mas é diferente daquele encontrado por estudos anteriores (GUY, 1981; SCHERRE; MACEDO, 2000). Como uma limitação do presente estudo, é preciso mencionar que há uma grande dificuldade em se fazer comparações confiáveis com estudos anteriores porque em cada um deles o contexto seguinte foi codificado de modo diferente. Portanto, sugere-se adotar um sistema de codificação mais detalhado quanto ao papel exercido pelas consoantes seguintes, como o adotado por Gryner e Macedo. 
O apagamento do /s/ pós-vocálico também foi influenciado significativamente pelo número de sílabas das palavras contidas no corpus. Nesse caso, quanto maior a palavra maiores foram as chances de haver apagamento. Isso também se confirma ao observarmos a proporção de apagamento em relação à tonicidade da sílaba final e ao número de sílabas (Tabela 2).

Tabela 2. Proporção de apagamento do / s/ em relação à tonicidade e ao número de sílabas

\begin{tabular}{|l|c|c|c|c|c|}
\hline \multirow{2}{*}{ Tonicidade } & \multicolumn{5}{|c|}{ Número de Sílabas } \\
\cline { 2 - 6 } & Monossílabo & Dissílabo & Trissílabo & Polissílabo & Total \\
\hline Átona & 1 & 26,2 & 32,8 & 40,4 & 23,1 \\
\hline Tônica & 1,6 & 4,5 & 12,5 & 12,5 & 2,5 \\
\hline Total & 1,4 & 22,2 & 31,2 & 39,3 & 15,2 \\
\hline
\end{tabular}

Observando os dados da Tabela 2, percebe-se que a proporção de apagamento do /s / aumenta na medida em que as palavras aumentam, independente da tonicidade da sílaba. Esta relação, no entanto, é muito mais nítida nas palavras com sílabas finais átonas.

\subsection{RESTRIÇÕES SOCIAIS DO APAGAMENTO DO /S/ PÓS-VOCÁLICO}

A análise quantitativa dos dados da presente pesquisa considerou o efeito de seis grupos de fatores sociais, a saber: sexo, faixa etária, nível de escolaridade, origem, raça ou cor e falante, como efeito aleatório. Dessa lista de variáveis independentes, apenas faixa etária e nível de escolaridade foram selecionados como significativamente relevantes para a ocorrência do apagamento do /s/ pós-vocálico. Nesta parte do texto, serão analisados e discutidos os resultados referentes aos grupos de fatores sociais, começando com os grupos significativamente relevantes.

A faixa etária dos participantes foi selecionada como a variável social de maior efeito significativo para a supressão do / s / em final de palavra. Considerando os resultados da Tabela 1, percebe-se que a variante zero é preferida pelos mais velhos e preterida pelos mais jovens. Dito de outra forma, os falantes com mais de 56 anos de idade (.84) tiveram um efeito bastante positivo para a ocorrência da variável zero. Os falantes mais jovens, por outro lado, desfavoreceram esta variável. Este foi o caso das pessoas com idades entre 36 e 55 (.41) e 18 e 35 (.21). Esse resultado era, de certa forma, esperado tendo em vista o desequilíbrio nos dados com relação à faixa etária e a escolaridade dos informantes que participaram deste estudo, como se pode ver na Tabela 3.

Tabela 3. Proporção de apagamento do / s / em relação à faixa etária e a escolaridade dos falantes

\begin{tabular}{|c|c|c|c|c|}
\hline & \multicolumn{4}{|c|}{ Nível de Escolaridade } \\
\hline Faixa Etária & 0 a 8 anos & 9 a 12 anos & Mais de 12 anos & Total \\
\hline 18 a 35 anos & -- & 4,4 & -- & 4,4 \\
\hline
\end{tabular}




\begin{tabular}{|l|c|c|c|c|}
\hline 36 a 55 anos & 9,3 & 8,5 & 7,1 & 8,4 \\
\hline Mais de 56 anos & 22,7 & 20,8 & 12,5 & 19,7 \\
\hline Total & 21,9 & 11,6 & 11,3 & 15,2 \\
\hline
\end{tabular}

Como se vê na Tabela 3, a análise não considera dados dos falantes mais jovens (18 a 35 anos) em todos os níveis de escolaridade. Todavia, a proporção de apagamento do /s/ entre os falantes das outras faixas etárias diminui na medida em que o nível de escolaridade aumenta. Esse dado certamente explica o fato de a variável nível de escolaridade ter sido selecionada como significativa para a aplicação da regra analisada neste estudo. Nesse grupo de fatores, a variante zero foi favorecida pelos falantes com escolaridade entre 0 e 8 anos (.63) e levemente desfavorecida pelos falantes que tinham entre 9 e 12 anos (.45) e mais de 12 anos (.40) de educação formal.

Apesar de não serem selecionados como significantes para a ocorrência do apagamento, as outras variáveis sociais também apresentam dados interessantes sobre essa variante. No caso do fator raça ou cor, vê-se um efeito positivo dos falantes que se autodeclararam pretos (.60), um efeito negativo entre os que se autodeclararam brancos (.41) e um efeito neutro entre os que se autodeclararam pardos (.48). Vale lembrar que das vinte e duas pessoas entrevistadas para este estudo, apenas duas $(9 \%)$ se autodeclararam brancas. No caso da variável origem regional, os participantes oriundos da região Sudeste, especificamente Minas Gerais e Espírito Santo, e Nordeste tiveram um efeito positivo no apagamento do /s/, enquanto os cariocas e fluminenses (não-cariocas) tiveram um efeito negativo nesta variante. Por fim, com relação à variável sexo, percebeuse um efeito positivo para o uso desta variante mais entre os homens do que entre as mulheres, algo que já tinha sido observado em estudos anteriores (CALLOU; MARQUES, 1975; GUY, 1981).

Nesta seção, foram apresentados e discutidos os resultados da análise quantitativa do apagamento do /s/ pós-vocálico em contexto de final de palavra. Em suma, tais resultados apontaram que esta variante foi afetada significativamente por quase todas as variáveis linguísticas incluídas no estudo. Estas variáveis foram vogal precedente, contexto seguinte, tonicidade, número de sílabas e classe gramatical. Dentre as variáveis sociais, apenas faixa etária e nível de escolaridade tiveram um efeito significativo para a ocorrência do apagamento do /s/.

\section{CONCLUSÃO}

Este artigo analisou a variação sociolinguística do apagamento do / s / pós-vocálico em final de palavra na fala de indivíduos e grupos de moradores da Cidade de Deus, bairro majoritariamente negro localizado na Zona Oeste da cidade do Rio de Janeiro. Foram incluídos na análise seis grupos de fatores linguísticos (vogal precedente, contexto seguinte, tonicidade, número de sílabas, classe gramatical, e palavra, como efeito aleatório) e seis grupos de fatores sociais (faixa etária, sexo, raça ou cor, origem regional, nível de escolaridade e falante, como efeito aleatório). Os resultados da análise de regressão 
logística dos dados revelaram que todas as variáveis linguísticas, exceto palavra, foram selecionadas como significantes para a ocorrência da variável dependente. Das variáveis sociais, foram selecionadas como significantes apenas faixa etária e nível de escolaridade.

Quanto ao seu condicionamento linguístico, o apagamento do /s/ foi favorecido em substantivos, adjetivos, advérbios e pronomes, depois de vogais posteriores, em palavras não oxítonas com três ou mais sílabas e seguido por pausa e consoantes coronais. Já entre os condicionamentos sociais, esta variante foi favorecida por falantes com mais de 56 anos e com até oito anos de educação formal.

Este estudo também discutiu a relevância de fatores como raça ou cor e migração como fundamentais para entender a realidade de comunidades urbanas marginalizadas, incluindo as favelas. Com isso, espera-se que outros pesquisadores da Sociolinguística interessados em estudar processos de variação e mudança em tais lugares possam começar seus trabalhos fazendo uma descrição mais realista da sua composição demográfica, o que eventualmente os levará a fazer descrições mais autênticas do uso linguístico de suas populações.

\section{REFERÊNCIAS}

AULER, M. A difusão lexical num fenômeno de aspiração do português. Revista de Estudos da Linguagem, v. 1, n. 1, p. 43-51, 1992. DOI: http://dx.doi.org/10.17851/22372083.1.1.43-51

BEATON, M. E.; WASHINGTON, H. B. Slurs and the indexical field: the pejoration and reclaiming of favelado 'slum-dweller'. Language Sciences, v. 1, p. 1-10, 2014. DOI: https://doi.org/10.1016/j.langsci.2014.06.021

BRESCANCINI, C. R. A aspiração da fricativa em posição de coda no dialeto florianopolitano - variação e teoria. Organon, v. 18, n. 36, p. 93-99, 2004. DOI: https://doi.org/10.22456/2238-8915.31157

BRESCANCINI, C. R. A fricativa em posição de coda no PB. In: RAMOS, J. M. (Ed.). Estudos sociolinguísticos: os quatro vértices do GT da ANPOLL. Belo Horizonte, MG: Editora da Faculdade de Letras, UFMG, 2006. p. 6-20.

BRESCANCINI, C. R. A fricativa palato-alveolar e sua complexidade. 2002. 362f. Tese (Doutorado em Letras) - Pontifícia Universidade Católica do Rio Grande do Sul, Porto Alegre, 2002.

BRITO, E. P. A sociolinguistic analysis of word-final /s/ aspiration in a Rio de Janeiro favela. Journal of Portuguese Linguistics, v. 18, n. 1, p. 1-20, 2019. DOI: http://doi.org/10.5334/jpl.205

CALLOU, D. Um perfil da fala carioca. In: RIBEIRO, S. S. C.; COSTA, S. B. B.; CARDOSO, S. A. M. (Eds.). Dos sons às palavras: Nas trilhas da língua portuguesa. Salvador: EDUFBA, 2009. p. 129-152. 
CALLOU, D.; BRANDÃO, S. F. O processo de palatalização no português do Brasil. Linguística, v. 18, p. 57-73, 2006.

CALLOU, D.; LEITE, Y.; MORAES, J. Processo(s) de enfraquecimento consonantal no português do Brasil. In: ABAURRE, M. B. M.; RODRIGUES, A. C. S. (Eds.). Gramática do português falado. Campinas: UNICAMP, 2002. p. 537-555.

CALLOU, D.; MARQUES, M. H. D. O s implosivo na pronúncia do Rio de Janeiro. Littera, v. 5, p. 9-137, 1975.

CAVALLIERI, F.; VIAL, A. Favelas na cidade do Rio de Janeiro: o quadro populacional com base no Censo 2010. Rio de Janeiro: Instituto Pereira Passos - IPP. Disponível em: <http://portalgeo.rio.rj.gov.br/estudoscariocas/download\%5C3190_Favelasnacidaded oRiodeJaneiro_Censo_2010.PDF>. Acesso em: 4 abr. 2020.

FERREIRA, F. L. P. Variation in Ibero-Romance: a study of $/ \mathrm{s} /$ reduction in Braqilian Portuguese in comparison with Caribbean Spanish. 2001. 246 f. Tese (Doutorado em Espanhol e Português) - University of New Mexico, Albuquerque, 2001.

GUY, G. R. Linguistic variation in Brazilian Portuguese: aspects of the phonology, syntax, and language history. 1981. 391 f. Tese (Doutorado em Linguística) - University of Pennsylvania, Philadelphia, 1981.

GUY, G. R. Variation and change in Latin American Spanish and Portuguese. In: AMARAL, P.; CARVALHO, A. M. (Eds.). Portuguese-Spanish interfaces: diachrony, synchrony, and contact. Philadelphia: John Benjamins, 2014. p. 443-464.

GRYNER, H.; MACEDO, A. V. T. A pronúncia do -s pós-vocálico na região de Cordeiro - RJ. In: MOLLICA, M. C.; MARTELOTTA, M. E. (Eds.). Análises linguísticas: a contribuição de Alzira Macedo. Rio de Janeiro: UFRJ, 2000. p. 26-51.

HORA, D. da. Fricativas coronais: Análise variacionista. In: RONCARATI, C.; ABRAÇADO, J. (Eds.). Português brasileiro: contato linguístico, heterogeneidade e história. Rio de Janeiro: Viveiros de Castro, 2003. p. 69-89.

HORA, D. da; PEDROSA, J. L. R. Comportamento variável da fricativa coronal pósvocálica. In: RIBEIRO, S. S. C.; COSTA, S. B. B.; CARDOSO, S. A. M. (Eds.). Dos sons às palavras: nas trilhas da língua portuguesa. Salvador: EDUFBA, 2009. p. 111-128.

HORA, D. da; PEDROSA, J. L. R.; CARDOSO, W. Status da consoante pós-vocálica no português brasileiro: coda ou onset com núcleo não preenchido foneticamente? Letras de Hoje, v. 45, n. 1, p. 71-79, 2010.

INSTITUTO BRASILEIRO DE GEOGRAFIA E ESTATÍSTICA - IBGE. Censo demográfico 2010: aglomerados subnormais - primeiros resultados. Rio de Janeiro. Disponível em: <http://biblioteca.ibge.gov.br/visualizacao/periodicos/92/cd_2010_aglomerados_sub normais.pdf $>$. Acesso em: 20 dez. 2015. 
INSTITUTO DE PESQUISAS ECONÔMICAS APLICADAS - IPEA. Retrato das desigualdades de gênero e raça, 4. ed. Brasília: IPEA. Disponível em: <http://www.ipea.gov.br/retrato/>. Acesso em: 17 jan. 2015.

INSTITUTO PEREIRA PASSOS - IPP. Cadernos do Rio: migração. Rio de Janeiro: IPP. Disponível em: <http://www.armazemdedados.rio.rj.gov.br/arquivos/3297_migração.PDF>. Acesso em: 17 jan. 2015.

JOHNSON, D. E. Getting off the GoldVarb standard: introducing Rbrul for mixedeffects variable rule analysis. Linguistics and Language Compass, v. 3, p. 359-383, 2009. DOI: https://doi.org/10.1111/j.1749-818X.2008.00108.x

LABOV, W. The isolation of contextual styles. In: LABOV, W. Sociolinguistic patterns. Philadelphia: University of Pennsylvania Press, 1972a. p. 70-109.

LABOV, W. Some principles of linguistic methodology. Language in Society, v. 1, p. 97120, 1972b. DOI: https://doi.org/10.1017/S0047404500006576

LABOV, W. The social motivation of a sound change. Word, v. 19, p. 273-309, 1963. DOI: https://doi.org/10.1080/00437956.1963.11659799

LABOV, W. The social stratification of English in New York City. Washington: Center for Applied Linguistics, 1966.

LUCCHESI, D. A realização do /s/ implosivo no português popular de Salvador. In: RIBEIRO, S. S. C.; COSTA, S. B. B.; CARDOSO, S. A. M. (Eds.). Dos sons às palavras: nas trilhas da língua portuguesa. Salvador: EDUFBA, 2009. p. 83-110.

MELO, M. A. S. L. de. Direcionalidade da mudança sonora: o papel do item lexical e da estrutura social na direcionalidade da mudança sonora. 2017.141 f. Tese (Doutorado em Linguística) - Universidade Federal do Rio de Janeiro, Rio de Janeiro, 2017.

MEIRELLES, R.; ATHAIDE, C. Um país chamado favela. São Paulo: Gente, 2014.

MILROY, L.; GORDON, M. Sociolinguistics: method and interpretation. Malden, MA and Oxford: Blackwell, 2003.

MOTA, J. A. O -s em coda silábica na norma culta de Salvador. 2002. Tese (Doutorado em Língua Portuguesa) - Universidade Federal do Rio de Janeiro, Rio de Janeiro, 2002.

NYLUND, A. Phonological variation at the intersection of ethnoracial identity, place, and style in Washington, DC. 2013. 309 f. Tese (Doutorado em Linguística) - Georgetwon University, Washington, DC, 2013.

PERLMAN, J. Favela: four decades of living on the edges in Rio de Janeiro. Oxford: Oxford University Press, 2010.

RODRIGUES, C.; HORA, D. da. Main current processes of phonological variation. In: WETZELS, W. L.; COSTA, J.; MENUZZI, S. (Eds.). The handbook of Portuguese Linguistics. Malden, MA: Wiley-Blackwell, 2016. p. 504-525. 
ROTH-GORDON, J. Race and the Brazilian body: blackness, whiteness, and everyday language in Rio de Janeiro. Oakland, CA: University of California Press, 2017.

SCHERRE, M. M. P.; MACEDO, A. V. T. Restrições fonético-fonológicas e lexicais: o -s pós-vocálico no Rio de Janeiro. In: MOLLICA, M. C.; MARTELLOTA, M. E. (Eds.). Análises linguísticas: a contribuição de Alzira Macedo. Rio de Janeiro: UFRJ, 2000. p. 5264.

SCHILLING, N. Sociolinguistic fieldwork. Cambridge: Cambridge University Press, 2013.

WEINREICH, U.; LABOV, W.; HERZOG, M. Empirical foundations for a theory of language change. In: LEHMANN, W. P.; MALKIEL, Y. (Eds.). Directions for historical linguistics. Austin, TX: University of Texas Press, 1968. p. 95-188.

\section{ANEXO 1: QUESTIONÁRIO DA ENTREVISTA}

Tópico: Vida em geral no Rio de Janeiro (Itálico é usado para instruções para o

Entrevistador)

O que te trouxe para o Rio (para este bairro)?

Se nascido(a) aqui

Você tem alguma ideia de porquê seus pais vieram para cá?

Eles se mudaram muito até chegar aqui? Se sim, onde eles moraram? De que lugar eles gostaram mais... e por quê?

Você(s) sempre morou/moraram na Cidade de Deus? Nesta casa/Neste apartamento?

O que mudou nesta área desde que você era criança? Por exemplo, está mais

movimentada, mais (ou menos) segura, mais (ou menos) cara, lojas melhores (piores)...

Peça detalbes

Se não nascido(a) aqui

Há quantos anos você mora aqui no Rio?

Você se lembra por que você decidiu morar na Cidade de Deus?

Você procurou moradia/casa em outros lugares?

Como você encontrou esta casa/este apartamento?

Como é aqui comparado com o lugar onde você morava antes? Peça detalhes

Uma das coisas que eu quero saber é sobre quanto tempo você passa no seu bairro, na região, na cidade, e o que você faz nestes lugares.

Então, num dia de semana típico, por exemplo, o que você faz? Faça perguntas subsequentes Se trabalha Como você chega até o trabalho?

Ideias para perguntas subsequentes

Que tipo de transporte você usa para ir à outras partes da cidade?

Se dirige/ anda de bicicleta Como é o trânsito por aqui?

O que você acha do BRT (Bus Rapid Transit System que foi implementado em preparação para a Copa do Mundo de 2014 e as Olimpíadas de 2016)?

O que você faz num fim de semana típico? Faça perguntas subsequentes

Onde sua família (ou o resto da sua família) mora? 
Com que frequência vocês se encontram?

E onde a maioria dos seus amigos mora?

E na Cidade de Deus... você conhece/tem amigos(as) por aqui?

Se sim, como vocês se conheceram?

Suponha que você quisesse sair, para um restaurante, cinema, teatro... onde você iria?

Você quer continuar morando aqui na Cidade de Deus/Rio de Janeiro, ou gostaria de se mudar para outro lugar?

Se sim, para onde? Para sua terra natal? Para outro bairro/cidade? Por quê?

Quais são as vantagens e desvantagens de morar nesta área/no Rio de Janeiro?

Quais seriam as diferenças de estilo de vida entre as pessoas que moram aqui e as pessoas que moram na Zona Sul (do Rio de Janeiro), por exemplo?

Em geral, você acha que o lugar onde uma pessoa mora afeta o modo como ela é tratada por outras pessoas? Por quê/Por que não?

Como você sabe se uma pessoa é da área/vive na x ou área y? Faça perguntas subsequentes

Você já sofreu algum tipo de discriminação por morar nesta área?

Se sim $\mathrm{O}$ que aconteceu?

Você já assistiu ao filme Cidade de Deus?

Se sim Qual é a sua opinião sobre o filme?

Você concorda com a forma como a Cidade de Deus é retratada no filme? Por quê/Por que não?

Você ouviu falar sobre a visita que o Presidente Barack Obama fez à Cidade de Deus em 2011?

Se sim $\mathrm{O}$ que você acha disso?

Recebido em: 02/10/2019

Aprovado em: 07/12/2019

Publicado em: 30/12/2020 